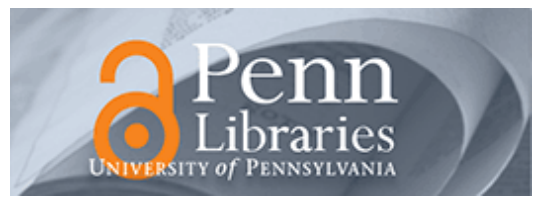

University of Pennsylvania

ScholarlyCommons

\title{
$5-2010$
}

\section{Human Bone Marrow Stromal Cells Display Variable Anatomic Site-Dependent Response and Recovery From Irradiation}

\author{
Monika Damek-Poprawa \\ University of Pennsylvania \\ Derek Stefanik \\ University of Pennsylvania \\ Lawrence Levin \\ University of Pennsylvania \\ Sunday O. Akintoye \\ University of Pennsylvania
}

Follow this and additional works at: https://repository.upenn.edu/dental_papers

Part of the Dentistry Commons

\section{Recommended Citation}

Damek-Poprawa, M., Stefanik, D., Levin, L., \& Akintoye, S. O. (2010). Human Bone Marrow Stromal Cells Display Variable Anatomic Site-Dependent Response and Recovery From Irradiation. Archives of Oral Biology, 55 (5), 358-364. http://dx.doi.org/10.1016/j.archoralbio.2010.03.010 


\title{
Human Bone Marrow Stromal Cells Display Variable Anatomic Site-Dependent Response and Recovery From Irradiation
}

\begin{abstract}
Objectives

Orofacial bone is commonly affected by osteoradionecrosis (ORN) during head and neck cancer radiotherapy possibly due to interactions of several factors including radiation damage to resident bone marrow stromal cells (BMSCs). Irradiation causes DNA damage, triggers p53-dependent signalling resulting in either cell-cycle arrest or apoptosis. In same individuals, disproportionately higher rapid growth of orofacial BMSCs relative to those of axial/appendicular bones suggests their response to radiation is skeletally site-specific. We hypothesised that survival and osteogenic recovery capacity of irradiated human BMSCs is site-dependent based on anatomic skeletal site of origin.
\end{abstract}

\section{Methods}

Early passage BMSCs from maxilla, mandible and iliac crest of four normal volunteers were exposed to 2.5 to 10 Gy gamma radiation to evaluate clonogenic survival, effects on cell cycle, DNA damage, p53-related response and in vivo osteogenic regenerative capacity.

\section{Results}

Orofacial bone marrow stromal cells (OF-MSCs) survived higher radiation doses and recovered quicker than iliac crest (IC-MSCs) based on clonogenic survival, proliferation and accumulation in G0G1 phase. Post-irradiation p53 level was relatively unchanged but expression of p21, a downstream effector was moderately increased in OF-MSCs. Re-establishment of in vivo bone regeneration was delayed more in irradiated IC-MSCs relative to OF-MSCs.

\section{Conclusions}

Effect of irradiation on human BMSCs was skeletal site-specific with OF-MSCs displaying higher radioresistance and quicker recovery than IC-MSCs.

\section{Keywords}

bone marrow stromal cells, bone regeneration, osteoradionecrosislonizing, radiation, jaws

\section{Disciplines \\ Dentistry}




\title{
Human bone marrow stromal cells display variable anatomic site- dependent response and recovery from irradiation
}

\author{
Monika Damek-Poprawa1 ${ }^{1}$, Derek Stefanik ${ }^{1,3}$, Lawrence M. Levin ${ }^{2}$, and Sunday O. \\ Akintoye ${ }^{1, *}$ \\ ${ }^{1}$ Department of Oral Medicine, University of Pennsylvania School of Dental Medicine, Philadelphia \\ PA. \\ ${ }^{2}$ Department of Oral and Maxillofacial Surgery, University of Pennsylvania School of Dental \\ Medicine, Philadelphia PA.
}

\begin{abstract}
Objectives-Orofacial bone is commonly affected by osteoradionecrosis (ORN) during head and neck cancer radiotherapy possibly due to interactions of several factors including radiation damage to resident bone marrow stromal cells (BMSCs). Irradiation causes DNA damage, triggers p53dependent signaling resulting in either cell-cycle arrest or apoptosis. In same individuals, disproportionately higher rapid growth of orofacial BMSCs relative to those of axial/appendicular bones suggests their response to radiation is skeletally site-specific. We hypothesized that survival and osteogenic recovery capacity of irradiated human BMSCs is site-dependent based on anatomic skeletal site of origin.
\end{abstract}

Methods-Early passage BMSCs from maxilla, mandible and iliac crest of four normal volunteers were exposed to 2.5 to $10 \mathrm{~Gy}$ gamma radiation to evaluate clonogenic survival, effects on cell cycle, DNA damage, p53-related response and in vivo osteogenic regenerative capacity.

Results-Orofacial bone marrow stromal cells (OF-MSCs) survived higher radiation doses and recovered quicker than iliac crest (IC-MSCs) based on clonogenic survival, proliferation and accumulation in $\mathrm{G}_{0} \mathrm{G}_{1}$ phase. Post-irradiation $\mathrm{p} 53$ level was relatively unchanged but expression of p21, a downstream effector was moderately increased in OF-MSCs. Re-establishment of in vivo bone regeneration was delayed more in irradiated IC-MSCs relative to OF-MSCs.

Conclusions-Effect of irradiation on human BMSCs was skeletal site-specific with OF-MSCs displaying higher radio-resistance and quicker recovery than IC-MSCs.

\section{Keywords}

Bone marrow stromal cells; bone regeneration; osteoradionecrosis; ionizing radiation; jaws

\footnotetext{
(C) 2010 Elsevier Ltd. All rights reserved.

*Corresponding Author, Please address all correspondence to: Sunday O. Akintoye BDS,DDS,MS, University of Pennsylvania, School of Dental Medicine, Department of Oral Medicine, The Robert Schattner Center Room 209, 240 South 40th Street, Philadelphia PA 19104, Phone: 215-898-9932, Fax: 215-573-7853, akintoye@ dental.upenn.edu.

${ }^{3}$ Current address: Department of Biology, Boston University, Boston MA

Publisher's Disclaimer: This is a PDF file of an unedited manuscript that has been accepted for publication. As a service to our customers we are providing this early version of the manuscript. The manuscript will undergo copyediting, typesetting, and review of the resulting proof before it is published in its final citable form. Please note that during the production process errors may be discovered which could affect the content, and all legal disclaimers that apply to the journal pertain.
} 


\section{Introduction}

Radiotherapy of head and neck cancers often results in jaw osteoradionecrosis (ORN). About $10 \%$ of oro-pharyngeal cancer survivors treated with low dose radiation develop ORN, but increases when doses exceeds $60 \mathrm{~Gy}$ and irradiated field is subsequently traumatized (1). Pathogenesis of ORN is attributed to radiation-induced hypoxic-hypocellular-hypovascular tissue because osteoblast proliferation, osteocyte number and vascularity are suppressed in irradiated bone (2). Ionizing radiation induces $\mathrm{G}_{2} / \mathrm{M}$ cell cycle arrest and triggers a $\mathrm{p} 53$ dependent signaling pathway that may induce apoptotic cell death (3). However, this response is variable and cell type-dependent because p53 response causes cell cycle arrest in untransformed cells (4) and apoptosis in transformed cells (5). The dynamic equilibrium between different $\mathrm{p} 53$ downstream effectors including $\mathrm{p} 21^{\text {Waf1/Cip1 }}$ determines cell cycle progression and cell fate (6).

Specific cellular mechanisms initiating site-specific osteonecrosis are unclear making it challenging to heal osteonecrosis without surgical intervention. While radiation alters cellular survival mechanisms in bone cells (7-9), it is still unclear if bone marrow stromal cells (BMSCs) respond disparately to radiation in a skeletal site-dependent fashion to hinder bone healing. We hypothesized that BMSCs respond to irradiation disparately based on anatomic skeletal site of origin. Using maxilla, mandible and iliac crest BMSCs and therapeuticallyrelevant radiation doses (10), we evaluated disparity of cell survival, p53-related response and in vivo osteogenic regenerative capacity of irradiated BMSCs. We report that in same individuals, orofacial BMSCs were apparently more radio-resistant than those of iliac crest.

\section{Materials and Methods}

\section{Isolation and culture of adult bone marrow stromal cells}

Bone marrow samples from iliac crest and trabecular bone from maxilla and mandible were harvested from four healthy teenage volunteers according to an Institutional Review Boardapproved protocol at the University of Pennsylvania, Philadelphia, PA as previously described (7). Nucleated cells from each sample were cultured to establish primary BMSC using $\alpha$ modified minimum essential medium ( $\alpha$-MEM; Gibco-Invitrogen, Carlsbad, CA) supplemented with $20 \%$ fetal bovine serum (FBS) (Equitech Bio, Kerville, TX), $100 \mathrm{U} / \mathrm{ml}$ penicillin, $100 \mathrm{mg} / \mathrm{ml}$ streptomycin sulfate and $2 \mathrm{mM}$ glutamine incubated at $37{ }^{\circ} \mathrm{C}$ in a humidified atmosphere of $5 \% \mathrm{CO}_{2}$ and air as previously described (7). Primary BMSCs from iliac crest (IC-MSCs) and maxilla and mandible orofacial bones (OF-MSCs) were further expanded or stored in liquid nitrogen until tested. All experiments were performed with early passage 2 to 4 BMSCs from four normal volunteers.

\section{Clonogenic cell survival assay}

OF-MSCs and IC-MSCs seeded at $1 \times 10^{4}$ cells $/ \mathrm{cm}^{2}$ in T-75 flasks were grown to confluence before exposure to $0,2.5,5,7.5$ or 10 Gray (Gy) gamma radiation at room temperature using a self-shielded Mark I ${ }^{137} \mathrm{Cs}$ irradiator with moving source (J. L. Shepherd, San Fernando, CA) at a rate of $1.25 \mathrm{~Gy} /$ minute. Control cells were maintained in the same conditions without irradiation. After trypsinization, cells were re-plated at increasing densities in 6-well plates. At 2 weeks and weekly medium renewals, cells were stained with crystal violet, washed with water and air-dried. Colonies containing $\geq 50$ cells were scored microscopically, surviving cells were analyzed using log-linear survival plot and linear quadratic modeling. $\mathrm{D}_{0}$ was calculated from slope, while $\alpha$ and $\beta$ were transformed using linear survival expression $-\ln$ (Surviving fraction/Dose) $=\alpha+\beta$ (Dose) $(11-13)$. 


\section{Cell viability assay}

OF-MSCs and IC-MSCs seeded in 96-well plates at $1 \times 10^{4}$ cells $/ \mathrm{cm}^{2}$ were subjected to $5 \mathrm{~Gy}$ radiation based on outcome of clonogenic survival assay above and clinical relevance. Timedependent viability of irradiated versus non-irradiated cells was assessed at baseline, 6, 24 and 48 hours post-irradiation with WST-1 cell viability assay (Roche Applied Science, Indianapolis IN) at absorbance of $450 \mathrm{~nm}$ using a Multiskan MCC automated microplate reader (Thermo Fisher Scientific, Waltham, MA) as previously described $(14,15)$.

\section{Cell cycle analysis}

Sub-confluent OF-MSCs and IC-MSCs in T-75 flasks were subjected to 5 Gy ionizing radiation. Cell populations in $\mathrm{G}_{0} / \mathrm{G}_{1}, \mathrm{~S}$ and $\mathrm{G}_{2} / \mathrm{M}$ phases of the cell cycle were analyzed 24 hours post-irradiation as previously described $(16,17)$ using Becton Dickinson FacStar Plus flow cytometer (Becton Dickinson, Franklin Lakes, NJ).

\section{DNA damage by Comet assay}

OF-MSCs and IC-MSCs were harvested 30 minutes after 5 Gy irradiation as described above. Non-irradiated cells were used as control to determine baseline endogenous DNA damage and similarly-matched BMSCs treated with $100 \mu \mathrm{M} \mathrm{H}_{2} \mathrm{O}_{2}$ were used as positive control for Comet tail formation. After alkaline unwinding, DNA was separated by alkaline electrophoresis for $30 \mathrm{~min}$ at $300 \mathrm{~mA}$, stained with SYBR Green I and assessed with Nikon Eclipse 80i fluorescent microscope (Nikon Instruments, Melville, NJ). Comet tail moment of $\geq 50$ randomly selected cells from each group was quantified with Comet Score software (TriTek Corp., Summerduck, VA) and DNA damage was analyzed by logarithmic transformation of comet scores.

\section{Apoptosis}

The In-situ Cell Death Detection Kit, Fluorescein (Roche Diagnostics, Indianapolis, IN) was used to assess apoptosis in three different experiments following the manufacturer's instructions. Briefly, OF-MSCs and IC-MSCs seeded at $8 \times 10^{3}$ cells/well in 8 -well chamber slides (Nalge Nunc Int., Rochester, NY) were exposed to 5 Gy radiation as described above. Control cells received no radiation. Apoptosis was assessed at 24 hours or 3 days postirradiation. Cells were washed with phosphate buffered saline (PBS pH 7.4) and fixed with $4 \%$ paraformaldehyde for 1 hour at room temperature. After permeabilization with $0.1 \%$ Triton $\mathrm{X}-100$ in $0.1 \%$ sodium citrate buffer, cells were stained with TUNEL reaction mixture (18) and nuclei co-stained with $2 \mu \mathrm{g} / \mathrm{mL}$ DAPI (4', 6-diamidino-2-pheylindole, Sigma-Aldrich, St. Louis, MO) for 10 minutes at room temperature in the dark. Number of TUNEL-positive cells per total cells was assessed with Nikon Eclipse 80i fluorescent microscope (Nikon Instruments, Melville, NJ).

\section{Radiation-induced changes in p53 level by Western blot}

Sub-confluent OF-MSCs and IC-MSCs seeded in duplicates $60 \mathrm{~mm}$ dishes at $1.5 \times 10^{4}$ cells/ $\mathrm{cm}^{2}$ were irradiated at $0,2.5$ or $5 \mathrm{~Gy}$. Total protein extracted 2 hours post-radiation using MPER Mammalian Protein Extraction Reagent (Pierce Biotechnology, Rockford, IL) was quantified with BCA protein assay (Pierce Biotechnology, Rockford, IL). $15 \mu \mathrm{g}$ protein per lane was loaded in 4-12\% Bis-Tris gel (Invitrogen, Carlsbad, CA) under reducing conditions. Western blotting was performed as previously described (19). Membranes were probed with 1:200 dilution each of mouse monoclonal anti-p53 (sc-126) and rabbit anti-p21 (sc-397) (all from Santa Cruz Biotechnology, Santa Cruz, CA) followed by incubation with specie-specific secondary antibody: sheep anti-mouse or sheep anti-rabbit conjugated to horse radish peroxidase (GE Healthcare, UK). Monoclonal antibody to human $\beta$-actin (ab6276, Abcam, Cambridge, MA) at 1:1000 was used as protein loading control. Immunoreactive blots were 
analyzed digitally with Kodak Image Station 4000MM (Molecular Imaging Systems, Carestream Health, Rochester, NY).

\section{Real time-PCR and p53-dependent gene profiling by microarray analysis}

Forty eight hours after irradiation of OF-MSCs and IC-MSCs with $0,2.5$ or 5 Gy as above, total mRNA was isolated using Trizol reagent (Invitrogen, Carlsbad, CA) following manufacturer's recommendations. cDNA was prepared from $2 \mu \mathrm{g}$ of total mRNA using oligo (dT) and SuperScript First-Strand Synthesis System for RT-PCR (Invitrogen, Carlsbad, CA). Real-time PCR reaction was performed in ABI 7300 Real-Time PCR System using Power SYBR Green PCR Master Mix (Applied Biosystems, Foster City, CA) and cDNA-specific primers designed with Primer Express software (Applied Biosystems, Foster City, CA) based on GenBank sequence (human p53, GenBank \# NM000546, forward, 5'-

CCCAGCCAAAGAAGAAACCA-3', reverse, 5'-CAGCTCTCGGAACATCTCGAA-3'; human p21, GenBank \# NM078467, forward, 5'-CCTGTCACTGTCTTGTACCCTTGT-3', reverse, 5'-TTTGGAGTGGTAGAAATCTGTCATG-3' and human TATA binding protein (TBP), GenBank \# M55654, forward, 5'-GGAGCTGTGATGTGAAGTTTCCTA-3', reverse, 5'-CCAGGAAATAACTCTGGCTCATAAC-3' used as normalizing control). Gene expression levels were normalized to TBP and presented as relative fold change using the $\Delta \Delta \mathrm{Ct}$ method (Applied Biosystems, Foster City CA). Using cDNAs prepared as above, $\mathrm{RT}^{2}$ Profiler PCR Array System (PAHS-0027, SuperArray Bioscience Corporation, Frederick, MD) was used to assess relative expression profiles of genes associated with p53-dependent signaling by RT-PCR reaction in ABI 7300 Real-Time PCR System (Applied Biosystems, Foster City, CA) (15).

\section{In vivo regenerative capacity of irradiated BMSCs}

Institutionally-approved animal protocol at University of Pennsylvania was used to assess in vivo bone regeneration of OF-MSCs and IC-MSCs exposed to $2.5 \mathrm{~Gy}$, a sub-lethal dose to allow for transplantation of more abundant surviving cells. From 2 of 4 subjects, $2 \times 10^{6}$ cells attached to $40 \mathrm{mg}$ of spheroidal hydroxyapatite/tricalcium phosphate (HA/TCP, particle size 0.5-1.0 mm, Zimmer, Warsaw, IN) were transplanted into the subcutis of 4-week-old immunocompromised nude female mice (NIH-III-nu, Charles River Laboratories, Wilmington, MA) as previously described (7). Transplants were harvested at 6 and 12 weeks, fixed in 4\% paraformaldehyde in PBS (pH 7.4) and decalcified in 10\% EDTA/PBS (pH 8.0) before paraffin embedding. Five micron sections were stained with hematoxylin/eosin for histological evaluation and semi-quantitative analysis of hard tissues regenerated as previously described $(14,15)$.

\section{Statistical analysis}

Results were expressed as mean \pm standard deviation. Statistical analysis was performed by two-way analysis of variance (ANOVA) followed by post-hoc comparisons with Holm-Sidak test using SigmaStat 3.1 statistical package (Systat Software, Inc., Chicago, IL). Statistical significance was set at $\mathrm{P}<0.05$.

\section{Results}

\section{Site-dependent radiation effects on BMSCs survival and cell cycle}

Clonogenic survival analysis showed disparate site and dose-dependent responsiveness of BMSCs to irradiation. The iliac crest cells (IC-MSCs) were most sensitive to radiation relative to maxilla and mandible cells $(\mathrm{OF}-\mathrm{MSCs})(\mathrm{P}<0.05)$. Linear quadratic modeling, and linear transformation of $\alpha$ and $\beta$ confirmed relative sensitivity of IC-MSCs over OF-MSCs $\left[\mathrm{D}_{0}=\right.$ 1.052 (iliac crest), -0.758 (maxilla) and -0.926 (mandible); $\tilde{\mathrm{n}}=0.4345$ (iliac crest), 1.321 
(maxilla) and 4.673 (mandible)]. (Figures 1A - C). OF-MSCs also recovered quicker from radiation effect and proliferated faster than IC-MSCs within 48 hours of 5 Gy irradiation (Figure 1D); a dose selected based on clonogenic survival data and clinical relevance. At baseline, there were more non-irradiated IC-MSCs in $\mathrm{G}_{0} \mathrm{G}_{1}$ at $81.31 \%$ compared to OF-MSCs at $67.57 \%$ and $65.44 \%$ for maxilla and mandible respectively (Figure $2 \mathrm{~A}$, top panel) but irradiation decreased $S$-phase cells in all cell types with corresponding increases in $\mathrm{G}_{0} \mathrm{G}_{1}$ phase (Figure 2A, lower panel) suggesting radiation-induced inhibition of S-phase entry. IC-MSCs had fewest S-phase cells and sustained apparently more DNA damage than OFMSCs as shown by Comet assay (Figures 2B) but there were no remarkable apoptotic responses in any of the cells based on either flow cytometry or $I n$-situ cell death analysis (data not shown).

\section{Radiation-induced changes in p53 responsiveness of BMSCs}

p53 level by Western blot was relatively unchanged post-irradiation irrespective of skeletal site (Figures $2 \mathrm{C}$ and $\mathrm{D}$ ) but the expression of $\mathrm{p} 21^{\mathrm{WAF} 1 / \mathrm{Cip} 1}$, a downstream effector, increased notably in OF-MSCs (Figures 2E). Microarray gene panel included p53-dependent genes implicated in the regulation of apoptosis, growth, proliferation, differentiation and DNA repair. While several genes were strongly over-expressed in OF-MSCs only, there were a few minimally under-expressed genes in both OF-MSCs and IC-MSCs (Table 1). Moreover, some genes that inhibit p53 activity like MDM2, MDM4 and RELA (known as p65) were unchanged in irradiated IC-MSCs but disparately over-expressed in OF-MSCs (Table 1). These complex gene interactions may underlie disparate BMSC responsiveness to irradiation.

\section{Bone formation by transplanted irradiated iliac crest, maxilla and mandible cells}

Irradiated OF-MSCs formed more histologically observable bone than IC-MSCs in vivo. While in vivo bone regeneration by OF-MSCs was observable by 6 weeks, IC-MSCs bone regeneration was further delayed. Interestingly, the three cell types recovered by 12 weeks to form in vivo bone quantitatively similar to that regenerated by non-irradiated cells (Figures 3A and B).

\section{Discussion}

Unique skeletal site-specific responses of BMSCs to irradiation have not been previously reported. Using BMSC samples from four subjects, we provide new evidence of site-disparity in the response of BMSCs from different skeletal sites to gamma radiation. It is significant to further understand biological responses of bone cells to external insults like radiation and drugs based on clinical indications that osteonecrosis affects craniofacial bones disparately with variable incidence of $3-14 \%$ in head and neck cancer patients compared to $0.44 \%$ in axial/ appendicular bones in gynecological cancers patients (14,20-22). Also, bisphosphonateassociated osteonecrosis occurs exclusively in the jaws apart from an isolated case report in the external auditory canal (22). Within the context of ORN, there are still no studies that addressed skeletal site-dependent cellular and molecular events that occur after irradiation.

Interestingly, despite the higher incidence of ORN in the jaws, we showed for the first time higher radio-resistance of OF-MSCs relative to IC-MSCs in same individuals. This suggests that OF-MSCs survived higher radiation doses and recovered quicker than IC-MSCs, a factor that may be moderating the damaging effects of irradiation in the jaws. p53 is a central element in cellular response to irradiation, and normal cells respond with a rapid but transitory accumulation of p53 protein; an essential process for cell cycle arrest at $\mathrm{G}_{1}$ checkpoint (23). Irradiated OF-MSCs and IC-MSCs demonstrated similar response by accumulating more $\mathrm{G}_{1^{-}}$ phase cells but OF-MSCs unlike IC-MSCs expressed higher p21 ${ }^{\mathrm{WAF} 1 / \mathrm{CIP} 1}$, a downstream effector of p53 implicated in $\mathrm{G}_{1}$ cell cycle arrest and DNA damage repair. This is consistent with the higher recovery capacity that we demonstrated in OF-MSCs and suggests the existence 
of repair processes that make OF-MSCs less susceptible to irradiation. When activated, p21 WAF1/CIP1, acts as a cyclin-dependent kinase inhibitor to block cell cycle progression and support cell survival (24). Exposure of cells to ionizing radiation causes significant early accumulation of $\mathrm{p} 21^{\mathrm{WAF} 1 / \mathrm{CIP} 1}$ while loss of $\mathrm{p} 21^{\mathrm{WAF} 1 / \mathrm{CIP} 1}$ in ATM-deficient mice severely sensitized their fibroblasts to radiation $(25,26)$. Previously described association of increased $\mathrm{p} 21^{\mathrm{WAF} 1 / \mathrm{CIP} 1}$ with ability to resist radiation-induced apoptosis indicate that radio-resistance of OF-MSCs may result from higher $\mathrm{p} 21^{\mathrm{WAF} 1 / \mathrm{CIP} 1}$ level (27).

Irradiated BMSCs in this study apparently did not undergo apoptotic death because In-situ apoptotic assay was negative and we have found no significant changes in BAX expression (data not shown), the death promoting gene that serves as a p53-dependent apoptotic target (28). Hence, BMSC-susceptibility to radiation appears to be by cell cycle arrest similar to earlier report that p53 response in untransformed cells usually leads to cell cycle arrest rather than apoptosis (5). This cell-to-cell variability has been described in other studies that showed fibroblasts undergo cell cycle arrest in response to radiation whereas T cells undergo extensive apoptosis $(29,30)$. Although microarray analysis showed more significant increase in expression of other pro-apoptotic genes (31) in OF-MSCs (Table 1), the relative OF-MSC radio-resistance to radiation-related apoptosis may be enhanced by over expression of counter players like HK2 (32) and WT1 (Table 1) that inhibit p53-dependent apoptotic pathway (33). Additionally, radio-resistance of OF-MSCs may be further enhanced by over-expression of MDM2, MDM4 and RELA genes that mutually repress p53 (34). However, the role of each of these p53-related genes needs further clarification.

In vitro radio-resistance of OF-MSCs relative to IC-MSCs was further confirmed by in vivo bone regenerative capacity post-irradiation. OF-MSCs formed in vivo bone early at 6 weeks while bone formation by irradiated IC-MSCs was further delayed (Figure 3) confirming better OF-MSC post-radiation recovery and superior osteogenic differentiation. Interestingly, ICMSCs needed more recovery time (12 weeks) to regenerate equally appreciable bone in vivo. This pattern of higher in vivo osteogenic property of OF-MSCs that has been previously described in non-irradiated BMSCs (7) was maintained despite exposure to irradiation. Also, the three cell types post-irradiation, displayed appreciable in vivo osteogenic regenerative capacity similar to non-irradiated cells when given more recovery time of 12 weeks.

While age affects phenotypic and functional characteristics of human hematopoietic and bone marrow stromal progenitor cells (35), age effects were minimized in this study because the tissue samples were obtained from teenagers within a narrow age range. Our study also support previous reports using BMSCs from 4 individuals $(7,14,15)$ to provide additional evidence of skeletal-site specificity of BMSCs as well as site-disparity in survival and recovery of irradiated BMSCs obtained from oral and hip bones. Further elucidation of underlying mechanism is still needed, but this impressive radio-resistance of OF-MSCs may have a modulating effect on ORN severity. Also, recovery capacity of irradiated OF-MSCs may make it easier for osseointegration at donor-recipient interface of osteoradionecrotic lesions treated with autologous bone grafts.

\section{Acknowledgments}

We thank Drs. Kelly Jordan-Sciutto, Cagla Akay and Carolyn Gibson for their useful comments and Drs. Amit Maity and George Cerniglia for assistance with survival curve analysis. This project was supported in part with funds from University of Pennsylvania Research Foundation, USPHS/NCI/NIH grant 5K08CA120875-03 and support of Penn Center for Musculoskeletal Disorders funded by NIH/NIAMS research grant AR050950. 


\section{References}

1. Cronje FJ. A review of the Marx protocols: prevention and management of osteoradionecrosis by combining surgery and hyperbaric oxygen therapy. Sadj 1998;53(10):469-471. [PubMed: 10023268]

2. Gal TJ, Munoz-Antonia T, Muro-Cacho CA, Klotch DW. Radiation effects on osteoblasts in vitro: a potential role in osteoradionecrosis. Arch Otolaryngol Head Neck Surg 2000;126(9):1124-1128. [PubMed: 10979127]

3. Szymczyk KH, Shapiro IM, Adams CS. Ionizing radiation sensitizes bone cells to apoptosis. Bone 2004;34(1):148-156. [PubMed: 14751572]

4. Bates S, Hickman ES, Vousden KH. Reversal of p53-induced cell-cycle arrest. Mol Carcinog 1999;24 (1):7-14. [PubMed: 10029405]

5. Bates S, Vousden KH. Mechanisms of p53-mediated apoptosis. Cell Mol Life Sci 1999;55(1):28-37. [PubMed: 10065149]

6. Waldman T, Lengauer C, Kinzler KW, Vogelstein B. Uncoupling of S phase and mitosis induced by anticancer agents in cells lacking p21. Nature 1996;381(6584):713-716. [PubMed: 8649519]

7. Akintoye SO, Lam T, Shi S, Brahim J, Collins MT, Robey PG. Skeletal site-specific characterization of orofacial and iliac crest human bone marrow stromal cells in same individuals. Bone 2006;38(6): 758-768. [PubMed: 16403496]

8. Chaudhry MA. Biomarkers for human radiation exposure. J Biomed Sci 2008;15(5):557-563. [PubMed: 18454354]

9. Migliorati CA, Schubert MM, Peterson DE, Seneda LM. Bisphosphonate-associated osteonecrosis of mandibular and maxillary bone: an emerging oral complication of supportive cancer therapy. Cancer 2005;104(1):83-93. [PubMed: 15929121]

10. Li J, Kwong DL, Chan GC. The effects of various irradiation doses on the growth and differentiation of marrow-derived human mesenchymal stromal cells. Pediatr Transplant 2007;11(4):379-387. [PubMed: 17493217]

11. Cerniglia GJ, Pore N, Tsai JH, Schultz S, Mick R, Choe R, et al. Epidermal growth factor receptor inhibition modulates the microenvironment by vascular normalization to improve chemotherapy and radiotherapy efficacy. PLoS One 2009;4(8):e6539. [PubMed: 19657384]

12. Iliakis G, Metzger L, Muschel RJ, McKenna WG. Induction and repair of DNA double strand breaks in radiation-resistant cells obtained by transformation of primary rat embryo cells with the oncogenes H-ras and v-myc. Cancer Res 1990;50(20):6575-6579. [PubMed: 2208118]

13. McKenna WG, Weiss MC, Endlich B, Ling CC, Bakanauskas VJ, Kelsten ML, et al. Synergistic effect of the v-myc oncogene with H-ras on radioresistance. Cancer Res 1990;50(1):97-102. [PubMed: 2403420]

14. Stefanik D, Sarin J, Lam T, Levin L, Leboy PS, Akintoye SO. Disparate osteogenic response of mandible and iliac crest bone marrow stromal cells to pamidronate. Oral Dis 2008;14(5):465-471. [PubMed: 18938273]

15. Yu V, Damek-Poprawa M, Nicoll SB, Akintoye SO. Dynamic hydrostatic pressure promotes differentiation of human dental pulp stem cells. Biochem Biophys Res Commun. 2009

16. Delia D, Goi K, Mizutani S, Yamada T, Aiello A, Fontanella E, et al. Dissociation between cell cycle arrest and apoptosis can occur in Li-Fraumeni cells heterozygous for p53 gene mutations. Oncogene 1997;14(18):2137-2147. [PubMed: 9174049]

17. Nigam M, Ranjan V, Srivastava S, Sharma R, Balapure AK. Centchroman induces G0/G1 arrest and caspase-dependent apoptosis involving mitochondrial membrane depolarization in MCF-7 and MDA MB-231 human breast cancer cells. Life Sci 2008;82(11-12):577-590. [PubMed: 18279897]

18. Negoescu A, Lorimier P, Labat-Moleur F, Drouet C, Robert C, Guillermet C, et al. In situ apoptotic cell labeling by the TUNEL method: improvement and evaluation on cell preparations. J Histochem Cytochem 1996;44(9):959-968. [PubMed: 8773561]

19. Akintoye SO, Dasso M, Hay DI, Ganeshkumar N, Spielman AI. Partial characterization of a human submandibular/sublingual salivary adhesion-promoting protein. Arch Oral Biol 2002;47(5):337_ 345. [PubMed: 12015214] 
20. Feltl D, Vosmik M, Jirasek M, Stahalova V, Kubes J. Symptomatic osteoradionecrosis of pelvic bones in patients with gynecological malignancies-result of a long-term follow-up. Int J Gynecol Cancer 2006;16(2):478-483. [PubMed: 16681714]

21. Morrish RB Jr, Chan E, Silverman S Jr, Meyer J, Fu KK, Greenspan D. Osteonecrosis in patients irradiated for head and neck carcinoma. Cancer 1981;47(8):1980-1983. [PubMed: 7226091]

22. Sarin J, DeRossi SS, Akintoye SO. Updates on bisphosphonates and potential pathobiology of bisphosphonate-induced jaw osteonecrosis. Oral Dis 2008;14(3):277-285. [PubMed: 18336375]

23. Valerie K, Yacoub A, Hagan MP, Curiel DT, Fisher PB, Grant S, et al. Radiation-induced cell signaling: inside-out and outside-in. Mol Cancer Ther 2007;6(3):789-801. [PubMed: 17363476]

24. Harper JW, Adami GR, Wei N, Keyomarsi K, Elledge SJ. The p21 Cdk-interacting protein Cip1 is a potent inhibitor of G1 cyclin-dependent kinases. Cell 1993;75(4):805-816. [PubMed: 8242751]

25. Hill R, Bodzak E, Blough MD, Lee PW. p53 Binding to the p21 promoter is dependent on the nature of DNA damage. Cell Cycle 2008;7(16):2535-2543. [PubMed: 18719376]

26. Wang YA, Elson A, Leder P. Loss of p21 increases sensitivity to ionizing radiation and delays the onset of lymphoma in atm-deficient mice. Proc Natl Acad Sci U S A 1997;94(26):14590-14595. [PubMed: 9405657]

27. Waldman T, Zhang Y, Dillehay L, Yu J, Kinzler K, Vogelstein B, et al. Cell-cycle arrest versus cell death in cancer therapy. Nat Med 1997;3(9):1034-1036. [PubMed: 9288734]

28. Miyashita T, Reed JC. Tumor suppressor p53 is a direct transcriptional activator of the human bax gene. Cell 1995;80(2):293-299. [PubMed: 7834749]

29. Clarke AR, Purdie CA, Harrison DJ, Morris RG, Bird CC, Hooper ML, et al. Thymocyte apoptosis induced by p53-dependent and independent pathways. Nature 1993;362(6423):849-852. [PubMed: 8479523]

30. Di Leonardo A, Linke SP, Clarkin K, Wahl GM. DNA damage triggers a prolonged p53-dependent G1 arrest and long-term induction of Cip1 in normal human fibroblasts. Genes Dev 1994;8(21):2540_ 2551. [PubMed: 7958916]

31. Yang JY, Xia W, Hu MC. Ionizing radiation activates expression of FOXO3a, Fas ligand, and Bim, and induces cell apoptosis. Int J Oncol 2006;29(3):643-648. [PubMed: 16865280]

32. Budanov AV, Shoshani T, Faerman A, Zelin E, Kamer I, Kalinski H, et al. Identification of a novel stress-responsive gene Hi95 involved in regulation of cell viability. Oncogene 2002;21(39):60176031. [PubMed: 12203114]

33. Maheswaran S, Englert C, Bennett P, Heinrich G, Haber DA. The WT1 gene product stabilizes p53 and inhibits p53-mediated apoptosis. Genes Dev 1995;9(17):2143-2156. [PubMed: 7657166]

34. Wadgaonkar R, Collins T. Murine double minute (MDM2) blocks p53-coactivator interaction, a new mechanism for inhibition of p53-dependent gene expression. J Biol Chem 1999;274(20):13760 13767. [PubMed: 10318779]

35. Wagner W, Bork S, Horn P, Krunic D, Walenda T, Diehlmann A, et al. Aging and replicative senescence have related effects on human stem and progenitor cells. PLoS One 2009;4(6):e5846. [PubMed: 19513108] 

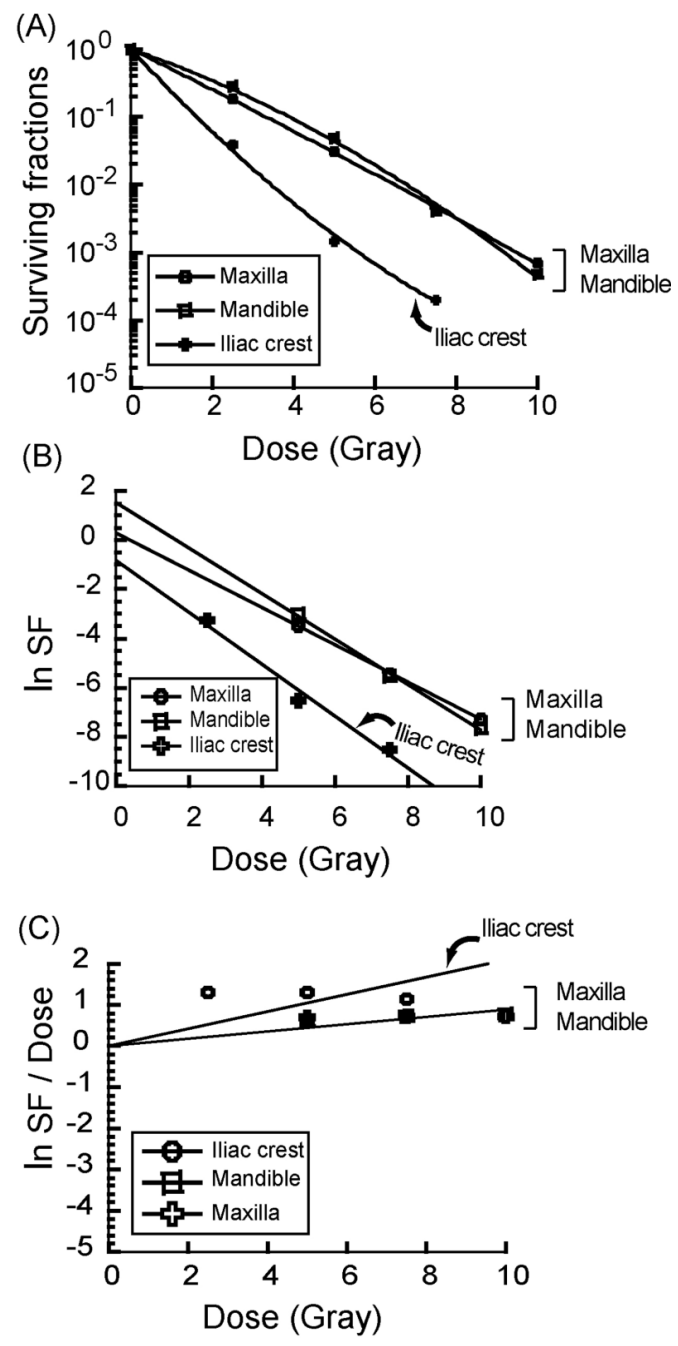

(D)

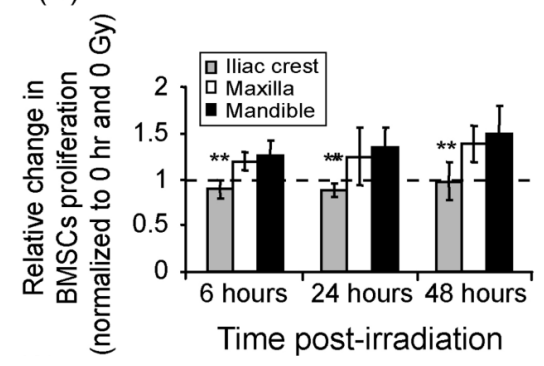

Figure 1.

Disparate site-dependent post-irradiation survival of BMSCs. A. Clonogenic radiation survival analysis showed site and dose-dependent radiobiological response of BMSCs from three skeletal sites. Maxilla and mandible BMSCs were more radio-resistant than iliac crest BMSCs ( $\mathrm{P}<0.05$, triplicate experiments of $\mathrm{n}=4$ subjects). B and C. Data was fitted to linear quadratic equation, $\mathrm{D}_{0}$ was calculated from slope, while $\alpha$ and $\beta$ were transformed using linear survival expression $-\ln ($ Surviving fraction/Dose $)=\alpha+\beta($ Dose $) .\left[\mathrm{D}_{0}=1.052\right.$ (iliac crest), -0.758 (maxilla) and -0.926 (mandible); $\tilde{\mathrm{n}}=0.4345$ (iliac crest), 1.321 (maxilla) and 4.673 (mandible)]. D. Maxilla and mandible also recovered quicker than iliac crest BMSCs as early as 6 hours post-irradiation $(* *=\mathrm{P}<0.01)$ 
(A)

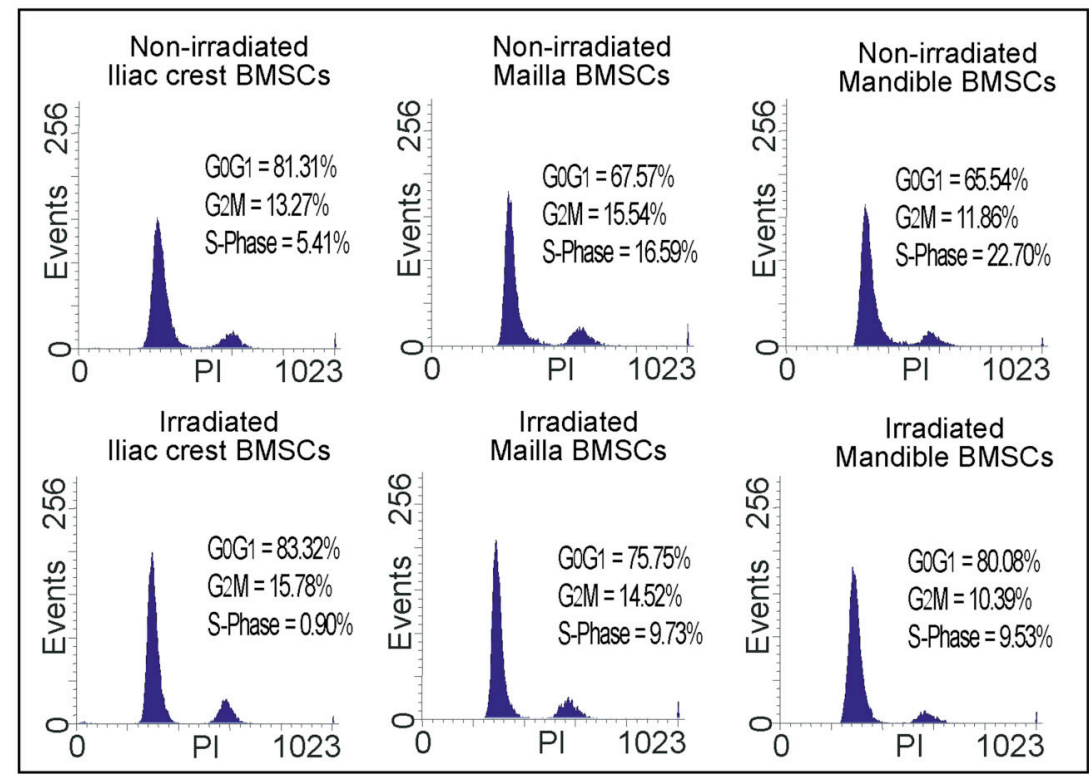

(C)

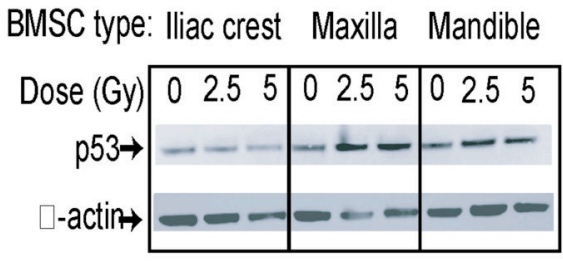

(D)

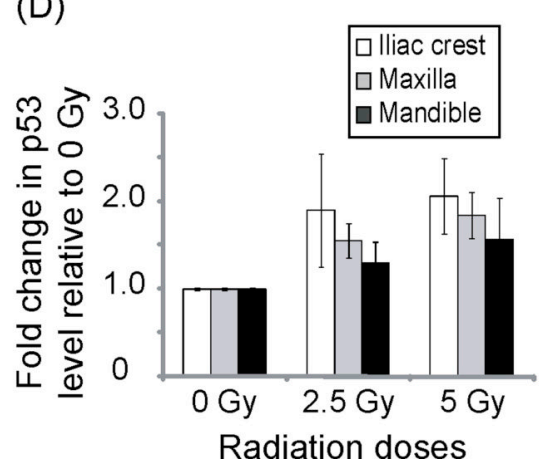

(B)

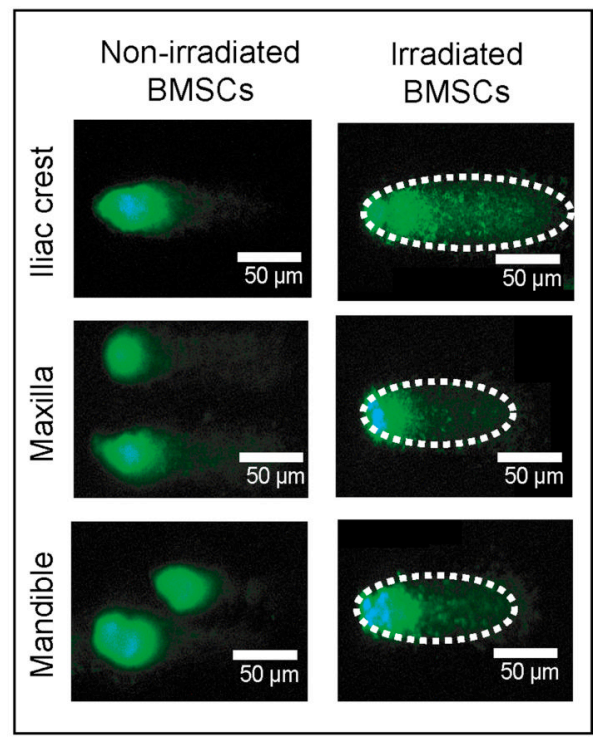

(E)

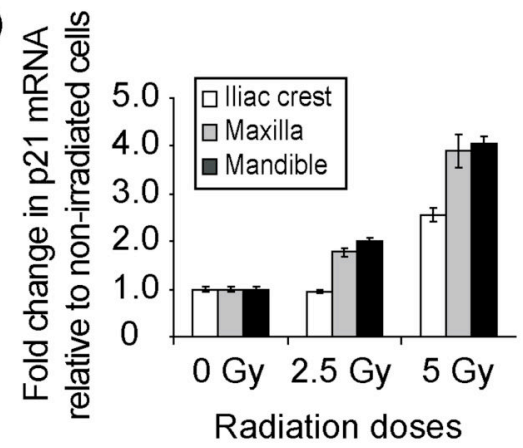

Figure 2.

Cell cycle distribution, DNA damage and p53-related changes in irradiated BMSCs. A. Cell cycle distribution of non-irradiated and irradiated BMSCs from the three skeletal sites indicate radiation-induced $\mathrm{G}_{0} \mathrm{G}_{1}$ arrest based on more BMSCs accumulation in $\mathrm{G}_{0} \mathrm{G}_{1}$ post-irradiation. B. Representative images of the comet tails visualized by SYBR Green I staining 30 minutes post-irradiation indicate more DNA damage in iliac crest relative to maxilla and mandible BMSCs (Analysis of relative changes in tail moment of $\geq 50$ cells indicate statistically significant differences between IC-MSCs and OF-MSCs, P < 0.01). C and D. Representative Western blots and p53 levels based on densitometric analysis from irradiated cells $(n=4$ subjects) showed disparate p53 levels based on immunoreactivity to mouse anti-human p53 antibody. E. The response to radiation based on $\mathrm{p} 21^{\text {Waf1/Cip1 }} \mathrm{mRNA}$ was higher in maxilla and mandible BMSCs ( $\mathrm{n}=4$ subjects) post-irradiation suggesting underlying mechanisms may be downstream of $\mathrm{p} 53$ signaling. 
(A) Non-irradiated
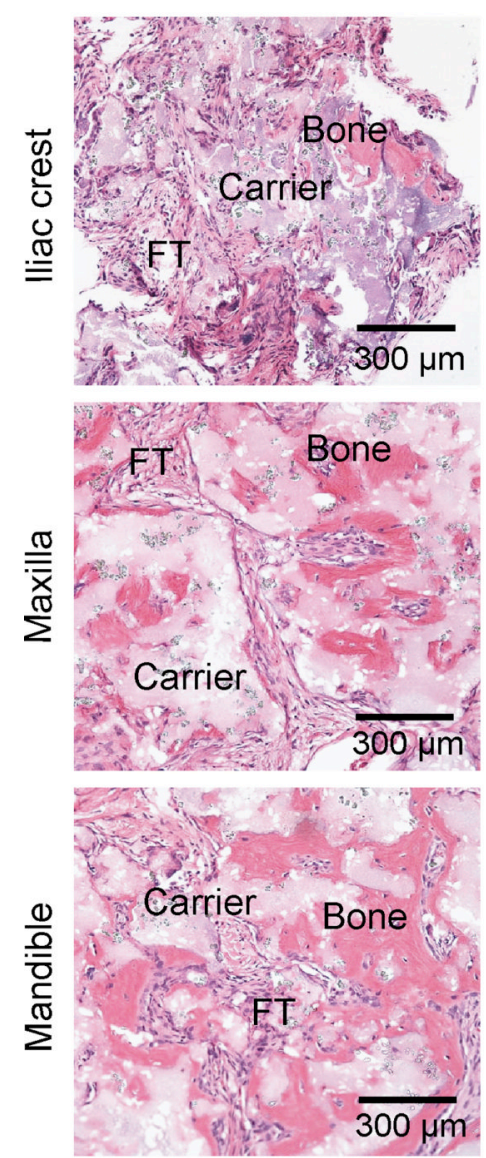

Irradiated
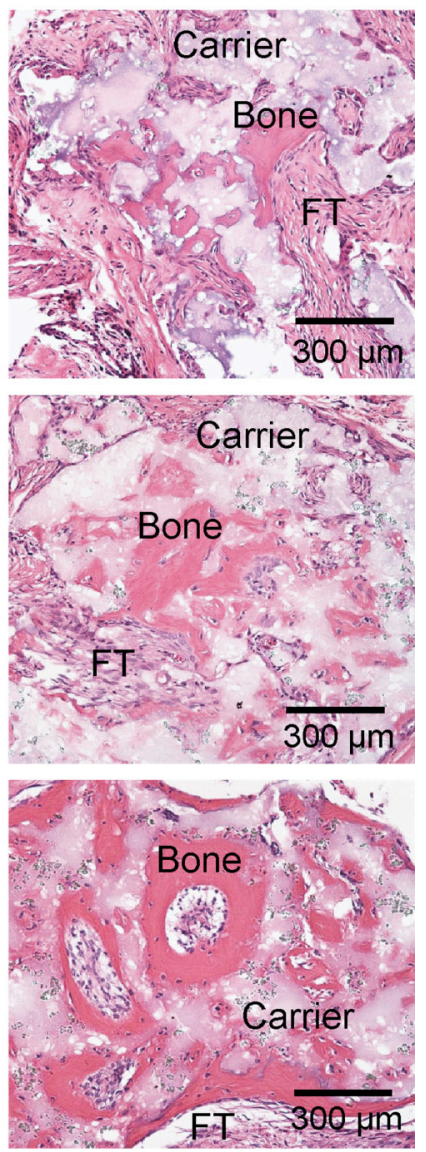

(B)

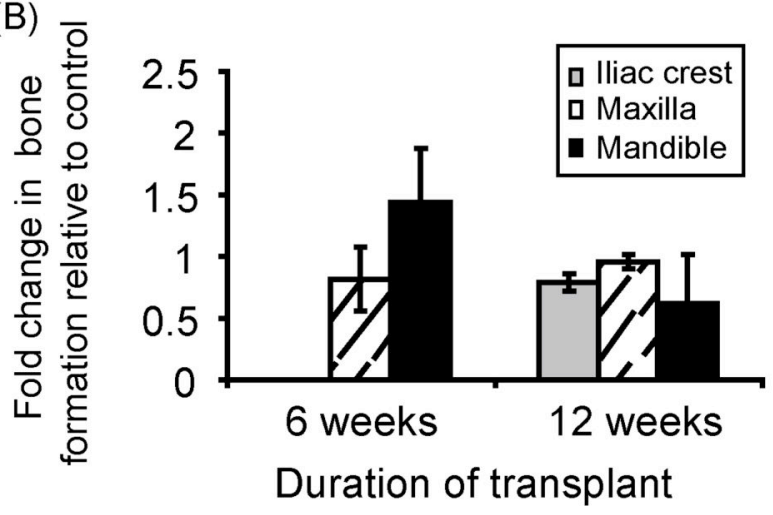

Figure 3.

In vivo bone formation by irradiated BMSCs. A. Hematoxylin/eosin-stained sections in vivo bone showed irradiated BMSCs recovered and formed appreciable bone by 12 weeks. B. Despite irradiation, 12 weeks allowed the three cell types to recover and form bone quantitatively similar to non-irradiated cells. (Histology sections representatives of BMSCs transplants from $\mathrm{n}=4$ subjects; $\mathrm{FT}=$ fibrous tissue; carrier $=$ hydroxyapatite/tricalcium phosphate). 
Table 1

Microarray analysis showing disparate changes in p53-related genes post-BMSCs irradiation

Genes Over-Expressed in Irradiated BMSCs compared with Non-Irradiated Control

\begin{tabular}{|c|c|c|c|c|c|}
\hline Cell Type & Gene Symbol & \multicolumn{2}{|l|}{ Gene Name } & \multirow{2}{*}{$\begin{array}{c}\begin{array}{c}\text { Fold } \\
\text { Change }\end{array} \\
8.0\end{array}$} & \multirow{2}{*}{$\begin{array}{l}\text { Group* } \\
a\end{array}$} \\
\hline \multirow{18}{*}{ Maxilla / Mandible } & FASLG & \multicolumn{2}{|l|}{ Fas ligand (TNF superfamily, member 6) } & & \\
\hline & GML & \multicolumn{2}{|l|}{ GPI anchored molecule like protein } & 8.4 & $b$ \\
\hline & IFNB1 & \multicolumn{2}{|l|}{ Interferon, beta 1 , fibroblast } & 8.6 & $a, b$ \\
\hline & LRDD & \multicolumn{2}{|l|}{ Leucine-rich repeats and death domain containing } & 4.9 & $a$ \\
\hline & TNF & \multicolumn{2}{|c|}{ Tumor necrosis factor (TNF superfamily, member 2) } & 6.9 & $a$ \\
\hline & TP73 & \multicolumn{2}{|l|}{ Tumor protein $\mathrm{p} 73$} & 4.1 & $b$ \\
\hline & WT1 & \multicolumn{2}{|l|}{ Wilms tumor 1} & 4.4 & $d$ \\
\hline & ATM & \multicolumn{2}{|l|}{ Ataxia telangiectasia mutated } & 4.0 & $b$ \\
\hline & CASP2 & \multicolumn{2}{|l|}{ Caspase 2} & 4.7 & $a$ \\
\hline & FOXO3 & \multicolumn{2}{|l|}{ Forkhead box $\mathrm{O} 3$} & 4.3 & $a$ \\
\hline & HK2 & \multicolumn{2}{|l|}{ Hexokinase 2} & 7.3 & $d$ \\
\hline & LRDD & \multicolumn{2}{|l|}{ Leucine-rich repeats and death domain containing } & 16.0 & $a$ \\
\hline & MDM2 & \multicolumn{2}{|l|}{ Mdm2, transformed 3T3 cell double minute 2} & 5.5 & $e$ \\
\hline & MDM4 & \multicolumn{2}{|l|}{ Mdm4, transformed 3T3 cell double minute 4} & 4.5 & $e$ \\
\hline & PCBP4 & \multicolumn{2}{|l|}{ Poly(rC) binding protein 4} & 9.9 & $a, b$ \\
\hline & RELA & \multicolumn{2}{|c|}{ V-rel re ticuloendotheliosis viral oncogene homolog A } & 12.0 & $e$ \\
\hline & SESN2 & \multicolumn{2}{|l|}{ Sestrin 2} & 13.5 & $a$ \\
\hline & TNFRSF10D & \multicolumn{2}{|l|}{ TNF receptor superfamily, member $10 \mathrm{~d}$} & 4.3 & $a$ \\
\hline \multicolumn{6}{|c|}{ Genes Under-Expressed in Irradiated BMSCs compared with Non-Irradiated Control } \\
\hline Cell Type & Gene Symbol & Gene Name & $\begin{array}{l}\text { Fold } \\
\text { Change }\end{array}$ & Group & \\
\hline \multirow{2}{*}{$\begin{array}{l}\text { Iliac } \\
\text { crest }\end{array}$} & P53AIP1 & p53- regulated apoptosis inducing protein 1 & 0.1 & $a$ & \\
\hline & PCAF & P300/CBP-associated factor & 0.2 & $a, b$ & \\
\hline \multirow{6}{*}{ Maxilla / Mandible } & BIRC5 & Baculoviral IAP repeat containing 5 (survivin) & 0.1 & $c$ & \\
\hline & $\mathrm{CCNB} 2$ & Cyclin B2 & 0.2 & $c$ & \\
\hline & $\mathrm{CDC} 2$ & Cell division cycle $2, \mathrm{G} 1$ to $\mathrm{S}$ and $\mathrm{G} 2$ to $\mathrm{M}$ & 0.2 & $c$ & \\
\hline & $\mathrm{PRC} 1$ & Protein regulator of cytokinesis 1 & 0.2 & $c$ & \\
\hline & PTTG1 & Pituitary tumor transforming 1 & 0.2 & $e$ & \\
\hline & CCNB2 & Cyclin B2 & 0.2 & $c$ & \\
\hline \multicolumn{6}{|l|}{ Groups: } \\
\hline \multicolumn{6}{|l|}{$a_{\text {pro-apoptotic genes }}$} \\
\hline \multicolumn{6}{|c|}{$b$ genes involved in cell cycle arrest } \\
\hline$c$ genes implicated in & ogression throug & cell cycle & & & \\
\hline
\end{tabular}


$e_{\text {genes inhibiting p53 transcriptional activity }}$ 